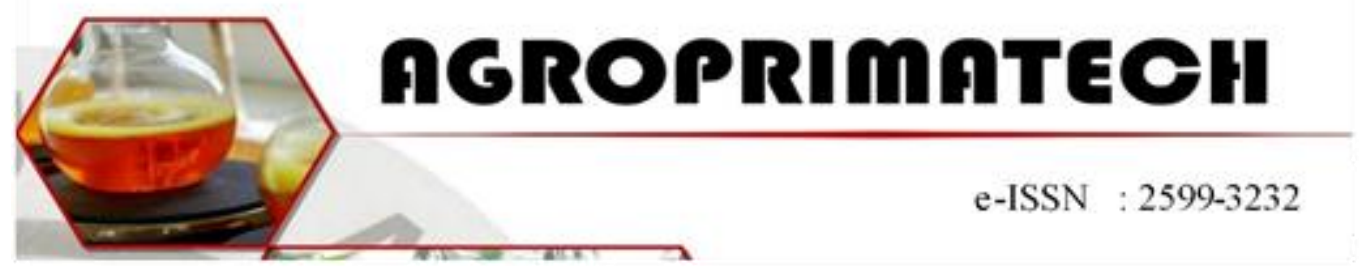

\title{
PERTUMBUHAN DAN HASIL TANAMAN SELADA (Lactuca sativa L.) AKIBAT JENIS MEDIA TANAM HIDROPONIK DAN KONSENTRASI NUTRISI AB MIX
}

\author{
MERIATY ${ }^{1}$, ARVITA SIHALOHO ${ }^{2}$, KIKI DWI PRATIWI ${ }^{3}$ \\ ${ }^{1,2}$ Staf Pengajar Program Studi Agroteknologi Fakultas pertanian USI \\ ${ }^{3}$ Mahasiswa Program Studi Agroteknologi Fakultas pertanian USI \\ Email: meriaty@gmail.com
}

\begin{abstract}
ABSTRAK
Penelitian ini dilakukan mulai dari bulan Februari 2020 sampai dengan April 2020, yang dilaksanakan di Jalan Naga Bonar, Kecamatan Siantar, Kabupaten Simalungun, dengan ketinggian tempat $\pm 400 \mathrm{~m}$ dpl. Tujuan penelitian : untuk mengetahui pertumbuhan dan hasil tanaman selada akibat jenis media tanam hidroponik dan konsentrasi nutrisi ab mix serta interaksi kedua perlakuan. Penelitian ini menggunakan Rancangan Acak Kelompok (RAK) Faktorial dengan dua faktor yaitu Faktor pertama: Jenis media tanam hidroponik (M) terdiri dari 3 taraf yaitu: $\mathrm{M}_{1}=$ Rockwool, $\mathrm{M}_{2}=$ Arang Sekam dan $\mathrm{M}_{3}=$ Cocopeat. Faktor kedua : Konsentrasi nutrisi ab mix $(\mathrm{N})$ yang terdiri dari 3 taraf yaitu: $\mathrm{N}_{1}=400 \mathrm{ppm}, \mathrm{N}_{2}=$ 800 ppm , dan $\mathrm{N}_{3}=1200$ ppm , parameter yang diamati adalah : Tinggi tanaman $(\mathrm{cm})$, Luas daun $\left(\mathrm{cm}^{2}\right)$, Bobot akar $(\mathrm{g})$, dan Bobot tanaman $(\mathrm{g})$. Perlakuan jenis media tanam berpengaruh terhadap tinggi tanaman, luas daun, jumlah daun, bobot akar, dan bobot tanaman. Tingkat konsentrasi nutrisi Ab Mix juga berpengaruh nyata terhadap tinggi tanaman, luas daun, bobot akar, dan bobot tanaman. Interaksi Jenis media tanam dan konsentrasi nutrisi Ab Mix berpengaruh tidak nyata terhadap tinggi tanaman, luas daun, bobot akar dan bobot tanaman.
\end{abstract}

Kata kunci: Media Tanam Hidroponik, Konsentrasi Ab Mix, Tanaman Selada.

\section{PENDAHULUAN}

Selada (Lactuca sativa L.) merupakan salah satu tanaman sayuran yang memiliki nilai ekonomi yang tinggi, bentuknya yang menarik serta kandungan gizinya yang banyak membuat tanaman ini berpotensi untuk terus dibudayakan. Tanaman selada dibudidayakan untuk diambil daunnya dan dimanfaatkan terutama untuk lalapan, perlengkapan sajian masakan dan hiasan hidangan. 
Selada juga memiliki banyak kandungan gizi dan vitamin antara lain Kalsium, Fosfor, Besi, Vitamin A, $B$, dan C (Setyaningrum dan Saparinto, 2011).

Selada memiliki peluang pasar yang cukup besar, baik untuk memenuhi kebutuhan pasar domestik maupun internasional. Permintaan yang tinggi baik pasar di dalam maupun diluar negeri menjadikan komoditi hortikultura ini memiliki nilai ekonomi yang tinggi, sehingga dapat meningkatkan pendapatan masyarakat. Sementara sumber daya alam untuk dibudidayakan di dalam negeri peluangnya cukup besar karena banyak daerah yang sangat cocok untuk budidaya selada. Berdasarkan data Badan Pusat Statistik (2014) produksi tanaman selada di indonesia dari tahun 2010 sampai 2013 sebesar 283.770 ton, 280.969 ton, 294.934 ton, dan 300.961 ton.

Teknologi hidroponik dapat menjadi solusi dalam menangani penurunan luas lahan pertanian yang sudah banyak dikonversikan menjadi perumahan, bahwa penurunan luas lahan pertanian terjadi cukup tinggi dalam kurun waktu 7 tahun. Dari tahun 2006 ke tahun 2009 terjadi sedikit penurunan, sedangkan dari tahun 2009 ke tahun 2012 terjadi penurunan yang cukup besar. Hal ini menyebabkan ketersediaan lahan pertanian semakin sempit sehingga produksi tanaman yang dihasilkan berkurang namun kebutuhan akan komoditas sayuran terus meningkat dan harus dipenuhi.

Salah satu sistem hidroponik yang sederhana ialah sistem wick (sumbu). Sistem ini dapat dioperasikan tanpa tergantung adanya energi listrik karena tidak memerlukan pompa untuk resirkulasi larutan hara. Hal ini menyebabkan sistem ini menjadi lebih sederhana, mudah dioperasikan, dan murah, sehingga berpotensi untuk dikembangkan pada tingkat petani kecil. Pada sistem ini larutan nutrisi disampaikan ke akar tanaman melalui sumbu. Hidroponik dengan sistem ini cocok digunakan untuk budidaya tanaman rendah seperti sayuran. Budidaya selada dengan sistem hidroponik dapat dipanen setelah 6 minggu setelah tanam dengan menghasilkan produksi maksimal pada interval waktu yang sesuai (Lingga, 2005).

Media tanam adalah media tumbuh bagi tanaman yang dapat memasok sebagian unsur-unsur hara yang dibutuhkan oleh tanaman. Media tanam (media tumbuh) merupakan salah unsur penting dalam menunjang pertumbuhan tanaman secara baik. Sebagian besar unsur-unsur hara yang dibutuhkan tanaman dipasok melalui media tanaman. Selanjutnya diserap oleh perakaran dan digunakan untuk proses fisiologis tanaman. Persyaratan terpenting untuk media tanam hidroponik harus ringan dan porus (berpori) agar air hara dapat masuk kedalamnya sehingga akar tanaman bisa menyerap hara. Media tanam hidroponik yang paling sering digunakan untuk budidaya antara lain: rockwool, arang sekam dan serbuk sabut kelapa (cocopeat) (Setyoadji, 2015).

Hal yang perlu diperhatikan dalam budidaya hidroponik adalah larutan nutrisi yang merupakan faktor penting untuk pertumbuhan dan kualitas hasil tanaman hidroponik, sehingga harus tepat dari segi jumlah komposisi ion nutrisi dan suhu. Nutrisi diberikan dalam bentuk larutan yang mengandung unsur makro dan mikro di dalamnya (Andhika, 2017). 


\section{Metode Penelitian}

Penelitian ini dilakukan mulai dari bulan Februari 2020 sampai dengan April 2020 Penelitian ini dilaksanakan di Jalan Naga Bonar, Kecamatan Siantar, Kabupaten Simalungun, dengan ketinggian tempat $\pm 400 \mathrm{~m}$ dpl. Tujuan penelitian adalah untuk mengetahui pertumbuhan dan hasil tanaman selada akibat jenis media tanam hidroponik dan konsentrasi nutrisi ab mix serta interaksi jenis media tanam hidroponik dan konsentrasi nutrisi ab mix. Penelitian ini menggunakan Rancangan Acak Kelompok (RAK) Faktorial dengan dua faktor perlakuan yaitu Faktor pertama: Jenis media tanam hidroponik (M) terdiri dari 3 taraf perlakuan yaitu: $M_{1}=$ Rockwool, $M_{2}=$ Arang Sekam, $\mathrm{M}_{3}=$ Cocopeat. Faktor kedua adalah Konsentrasi nutrisi ab mix $(\mathrm{N})$ yang terdiri dari 3 taraf perlakuan yaitu: $N_{1}=$ $400 \mathrm{ppm}(30 \mathrm{ml}$ stok $\mathrm{A}+30 \mathrm{ml}$ stok
B)Nutrisi $A b$ Mix, $\mathrm{N}_{2}=800$ ppm (60 ml stok $A+60 \mathrm{ml}$ stok B)Nutrisi Ab Mix, dan $\mathrm{N}_{3}=1200$ ppm (90 ml stok $A+$ $90 \mathrm{ml}$ stok B) Nutrisi Ab Mix.

Parameter Yang Diamati : Tinggi tanaman $(\mathrm{cm})$, Luas daun $\left(\mathrm{cm}^{2}\right)$, Bobot akar (g), dan Bobot tanaman (g).

\section{Hasil dan Pembahasan}

1. Tinggi Tanaman Selada $(\mathrm{cm})$ Data rata rata tinggi tanaman selada dan analisi sidik ragam diperoleh bahwa perlakuan jenis media tanam hidroponik dan konsentrasi nutrisi $A B$ Mix berpengaruh nyata terhadap tinggi tanaman selada pada umur 7, 14, dan 21 HST. Sedangkan interaksi kedua perlakuan berpengaruh tidak nyata.

Untuk mengetahui perbedaan antar perlakuan dilakukan dengan pengujian uji beda nyata jujur (BNJ) $5 \%$ pada Tabel 1.

Tabel 1. Uji Beda Rata-rata Tinggi $(\mathrm{cm})$ Tanaman Selada Akibat Pemberian Jenis Media Tanam Hidroponik dan Konsentrasi Nutrisi AB Mix Umur 7, 14, dan 21 (HST).

\begin{tabular}{cccc}
\hline \multirow{2}{*}{ Perlakuan } & \multicolumn{3}{c}{ Rata -rata Tinggi Tanaman } \\
\cline { 2 - 4 } & 7 HST & 14 HST & 21 HST \\
\hline $\mathrm{M}_{1}$ & $4.96 \mathrm{a}$ & $6.96 \mathrm{a}$ & $12.33 \mathrm{a}$ \\
$\mathrm{M}_{2}$ & $3.60 \mathrm{~b}$ & $5.88 \mathrm{~b}$ & $10.95 \mathrm{~b}$ \\
$\mathrm{M}_{3}$ & $3.29 \mathrm{~b}$ & $4.92 \mathrm{c}$ & $10.57 \mathrm{~b}$ \\
\hline $\mathrm{N}_{1}$ & $3.53 \mathrm{~b}$ & $5.40 \mathrm{~b}$ & $10.97 \mathrm{~b}$ \\
$\mathrm{~N}_{2}$ & $3.82 \mathrm{~b}$ & $6.00 \mathrm{a}$ & $11.16 \mathrm{~b}$ \\
$\mathrm{~N}_{3}$ & $4.51 \mathrm{a}$ & $6.36 \mathrm{a}$ & $11.71 \mathrm{a}$ \\
\hline $\mathrm{M}_{1} \mathrm{~N}_{1}$ & 3.97 & 6.39 & 11.87 \\
$\mathrm{M}_{1} \mathrm{~N}_{2}$ & 5.00 & 6.91 & 12.31 \\
$\mathrm{M}_{1} \mathrm{~N}_{3}$ & 5.90 & 7.59 & 12.80 \\
$\mathrm{M}_{2} \mathrm{~N}_{1}$ & 3.41 & 5.33 & 10.59 \\
$\mathrm{M}_{2} \mathrm{~N}_{2}$ & 3.44 & 6.10 & 10.89 \\
$\mathrm{M}_{2} \mathrm{~N}_{3}$ & 3.96 & 6.21 & 11.36 \\
$\mathrm{M}_{3} \mathrm{~N}_{1}$ & 3.21 & 4.49 & 10.46 \\
$\mathrm{M}_{3} \mathrm{~N}_{2}$ & 3.02 & 4.98 & 10.29 \\
$\mathrm{M}_{3} \mathrm{~N}_{3}$ & 3.66 & 5.29 & 10.96 \\
\hline $\mathrm{An}_{3}$ &
\end{tabular}

Keterangan :Angka yang diikuti oleh notasi yang sama pada kolom yang sama berbeda tidak nyata pada taraf $5 \%$. 


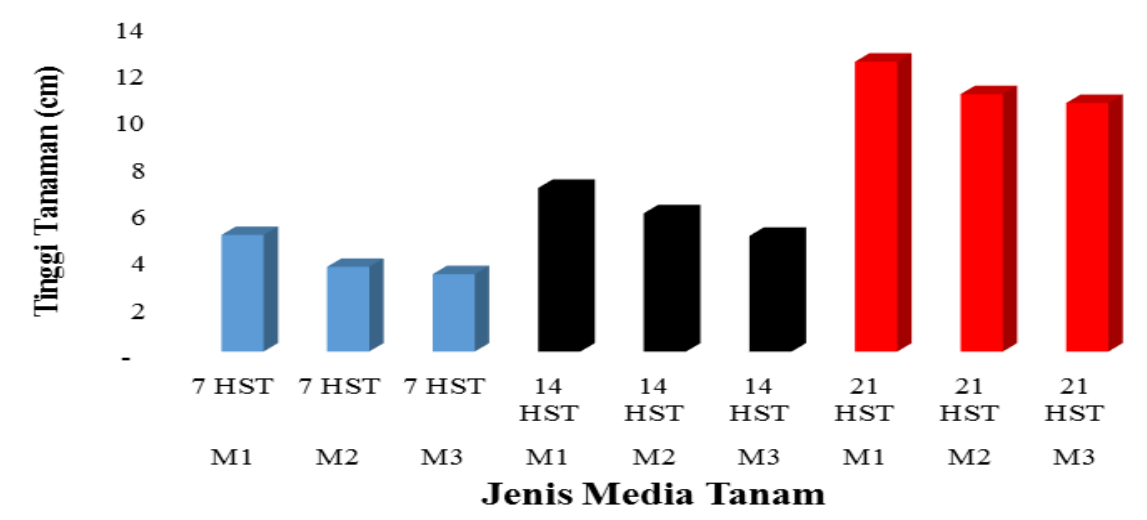

Gambar 1. Histogram Pengaruh Jenis Media Tanam Terhadap Tinggi Tanaman (cm) Selada Umur 7, 14 dan 21 HST

Dari tabel 1 dan gambar 1 dapat dilihat bahwa jenis media tanam rockwool $\left(\mathrm{M}_{1}\right)$ berbeda nyata dengan $\mathrm{M}_{2}$ dan $\mathrm{M}_{3}$, tetapi $\mathrm{M}_{2}$ dan $\mathrm{M}_{3}$ tidak berbeda nyata untuk 7 dan 21 HST tetapi untuk 14 HST dimana $M_{1}$

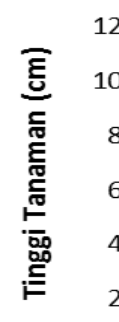

berbeda nyata dengan $M_{2}$ dan $M_{3}$ juga $M_{2}$ berbeda nyata dengan $M_{3}$. Untuk tanaman selada tertinggi terdapat pada perlakuan $\mathrm{M}_{1}$ untuk 7 HST (4.96 cm ), untuk 14 HST ( 6.96 $\mathrm{cm}$ ) dan untuk $21 \mathrm{HST}(12.33 \mathrm{~cm})$.

Gambar 2. Histogram Pengaruh Nutrisi Ab Mix Terhadap Tinggi Tanaman Selada Umur 7, 14 dan 21 HST

Dari tabel 1 dan gambar 2 dapat dilihat bahwa perlakuan Nutrisi ab Mix $\mathrm{N}_{1}$ berbeda tidak nyata dengan $\mathrm{N}_{2}$ tetapi berbeda nyata dengan $\mathrm{N}_{3}$ pada tinggi tanaman umur 7 dan 21 HST, tetapi pada umur 14 HST $\mathrm{N}_{1}$ berbeda nyata dengan $\mathrm{N}_{2}$ dan $N_{3}$ dimana $N_{2}$ dan $N_{3}$ berbeda tidak nyata. Tanaman tertinggi terdapat pada $\mathrm{N}_{3}$ yaitu $4.51 \mathrm{~cm}(7$ HST), $6.36 \mathrm{~cm}$ (14 HST) dan $11 \mathrm{~m} 71$ cm (21HST). Interaksi pada perlakuan jenis media tanam hidroponik dan konsentrasi nutrisi $\mathrm{Ab}$ Mix menunjukkan pengaruh yang tidak nyata. Namun pada perlakuan $\mathrm{M}_{1} \mathrm{~N}_{3}$ terdapat tinggi tanaman selada tertinggi baik pada 7, 14 dan $21 \mathrm{Hst}$.

2. Luas Daun $\left(\mathrm{cm}^{2}\right)$, bobot akar (g) dan bobot tanaman (g) 
Agroprimatech

Vol. 4 No. 2, April 2021

e-ISSN :2599-3232

Dari data rata rata luas daun, bobot akar dan bobot tanaman dan analisis sidik ragamnya diperoleh bahwa perlakuan jenis media tanam hidroponik dan konsentrasi nutrisi ab Mix berpengaruh nyata terhadap luas daun, bobot akar dan bobot tanaman

sedangkan interaksi kedua perlakuan berpengaruh tidak nyata.

Untuk mengetahui perbedaan antar perlakuan dilakukan dengan pengujian uji beda nyata jujur (BNJ) $5 \%$ pada Tabel 2.

Tabel 2. Uji Beda Rata-rata Luas Daun ( $\left.\mathrm{cm}^{2}\right)$, bobot akar (g) dan bobot tanaman (g) Selada Akibat Pemberian Jenis Media Tanam Hidroponik dan Konsentrasi Nutrisi ab Mix

\begin{tabular}{|c|c|c|c|}
\hline Perlakuan & $\begin{array}{l}\text { Rata-rata } \\
\text { Luas Daun } \\
\left(\mathrm{cm}^{2}\right)\end{array}$ & $\begin{array}{l}\text { Rata rata } \\
\text { bobot akar } \\
\quad(\mathrm{g})\end{array}$ & $\begin{array}{c}\text { Rata rata } \\
\text { bobot } \\
\text { Tanaman }(\mathrm{g})\end{array}$ \\
\hline $\mathrm{M}_{1}$ & $37.28 \mathrm{a}$ & $7.95 \mathrm{a}$ & $114.78 \mathrm{a}$ \\
\hline $\mathrm{M}_{2}$ & $34.75 \mathrm{~b}$ & $6.32 \mathrm{~b}$ & $99.36 \mathrm{~b}$ \\
\hline $\mathrm{M}_{3}$ & $32.21 \mathrm{c}$ & $5.29 \mathrm{~b}$ & $83.98 \mathrm{c}$ \\
\hline $\mathrm{N}_{1}$ & $33.02 \mathrm{~b}$ & $5.66 \mathrm{~b}$ & $93.13 \mathrm{c}$ \\
\hline $\mathrm{N}_{2}$ & $34.26 \mathrm{~b}$ & $6.35 \mathrm{~b}$ & $98.16 b$ \\
\hline $\mathrm{N}_{3}$ & $36.96 \mathrm{a}$ & $7.56 \mathrm{a}$ & $106.83 \mathrm{a}$ \\
\hline $\mathrm{M}_{1} \mathrm{~N}_{1}$ & 36.39 & 6.54 & 66.79 \\
\hline $\mathrm{M}_{1} \mathrm{~N}_{2}$ & 37.12 & 7.58 & 72.26 \\
\hline $\mathrm{M}_{1} \mathrm{~N}_{3}$ & 38.35 & 9.74 & 76.25 \\
\hline $\mathrm{M}_{2} \mathrm{~N}_{1}$ & 32.87 & 5.67 & 57.27 \\
\hline $\mathrm{M}_{2} \mathrm{~N}_{2}$ & 34.63 & 6.32 & 61.01 \\
\hline $\mathrm{M}_{2} \mathrm{~N}_{3}$ & 36.77 & 6.99 & 73.13 \\
\hline $\mathrm{M}_{3} \mathrm{~N}_{1}$ & 29.81 & 4.77 & 43.27 \\
\hline $\mathrm{M}_{3} \mathrm{~N}_{2}$ & 31.05 & 5.16 & 51.54 \\
\hline $\mathrm{M}_{3} \mathrm{~N}_{3}$ & 35.77 & 5.95 & 54.45 \\
\hline
\end{tabular}

Keterangan :Angka yang diikuti oleh notasi yang sama pada kolom yang sama berbeda tidak nyata pada taraf $5 \%$.

Dari tabel 2 , luas daun dapat dilihat bahwa pengaruh jenis media tanam $M_{1}$ berbeda nyata dengan $M_{2}$, dan $M_{3}$ dimana $M_{2}$ berbeda nyata dengan $\mathrm{M}_{3}$. Pengaruh nutrisi ab Mix terhadap luas daun dapat dilihat bahwa $N_{1}$ berbeda nyata dengan $N_{3}$ tetapi berbeda tidak nyata dengan $\mathrm{N}_{2}$, dimana $N_{2}$ berbeda nyata dengan $N_{3}$. Luas daun terbesar terdapat pada $\mathrm{M}_{1}$ yaitu $37.28 \mathrm{~cm}^{2}$ dan pada $\mathrm{N}_{3}$ yaitu $36.96 \mathrm{~cm}^{2}$. Interaksi jenis media tanam dan konsentrasi nutrisi Ab Mix berbeda tidak nyata pada parameter luas daun. 
Agroprimatech

Vol. 4 No. 2, April 2021

e-ISSN :2599-3232
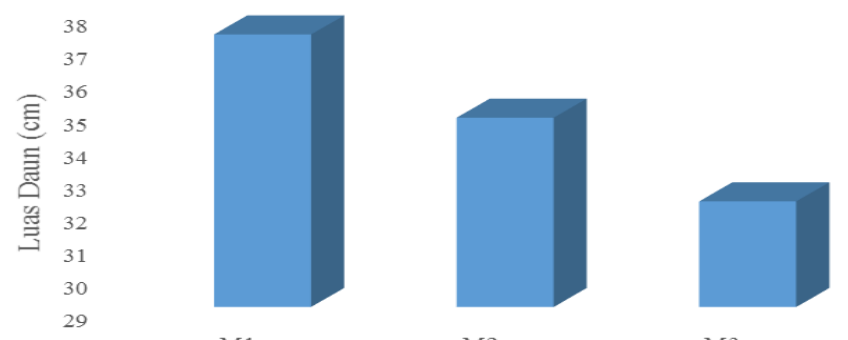

M1

Jenis Media Tanam

M3

Gambar 3. Histogram Pengaruh Jenis Media Tanam Terhadap Luas Daun $\left(\mathrm{cm}^{2}\right)$ Selada.

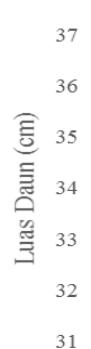

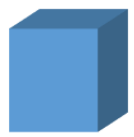

N1

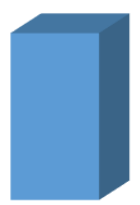

N2

Nutrisi Ab Mix

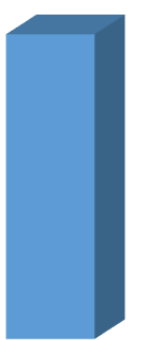

N3

Gambar 4. Histogram Pengaruh Nutrisi Ab Mix Terhadap Luas Daun $\left(\mathrm{cm}^{2}\right)$ Selada

Bobot akar dari tabel 2 dapat dilihat bahwa pengaruh jenis media tanam $M_{1}$ berbeda nyata dengan $M_{2}$ dan $M_{3}$ sedangkan $M_{2}$ dan $M_{3}$ berbeda tidak nyata. Untuk pengaruh nutrisi ab Mix terhadap bobot akar $\mathrm{N}_{1}$ berbeda tidak nyata dengan $N_{2}$ tetapi berbeda nyata dengan $\mathrm{N}_{3}$ dimana $\mathrm{N}_{2}$ berbeda nyata dengan $\mathrm{N}_{3}$. Bobot akar terbesar terdapat pada $M_{1}$ yaitu $7,95 \mathrm{~g}$ dan pada $\mathrm{N}_{3}$ yaitu $7,56 \mathrm{~g}$ Interaksi jenis media tanam dan konsentrasi nutrisi Ab Mix berbeda tidak nyata pada parameter bobot akar

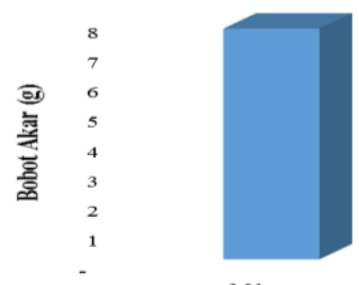

M1

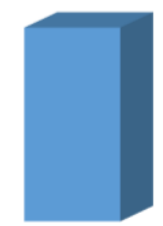

$\mathrm{M} 2$

Jenis Media Tanam

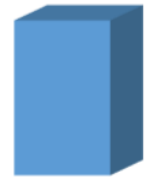

$\mathrm{M3}$

Gambar 5. Histogram Pengaruh Jenis Media Tanam Terhadap Bobot Akar (g) Selada 


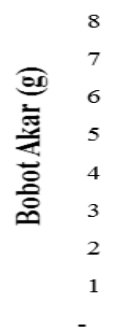

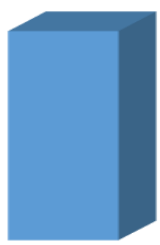

N1

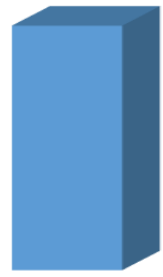

N2

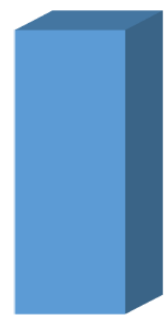

N3

Nutrisi Ab Mix

Gambar 6. Histogram Pengaruh Konsentrasi Nutrisi Ab Mix Bobot Akar (g)

Selada

Dari tabel 2 , bobot tanaman dapat dilihat bahwa pengaruh jenis media tanam $M_{1}$ berbeda nyata dengan $M_{2}$, dan $M_{3}$ dimana $M_{2}$ juga berbeda nyata dengan $M_{3}$. Pengaruh nutrisi ab Mix terhadap bobot tanaman dapat dilihat bahwa $N_{1}$ berbeda nyata dengan $N_{2}$ dan $N_{3}$ dimana $\mathrm{N}_{2}$ juga berbeda nyata dengan $\mathrm{N}_{3}$. Bobot Tanaman terbesar terdapat pada $\mathrm{M}_{1}$ yaitu $114,78 \mathrm{~g}$ dan pada $\mathrm{N}_{3}$ yaitu $106,83 \mathrm{~g}$. Interaksi jenis media tanam dan konsentrasi nutrisi Ab Mix berbeda tidak nyata pada parameter bobot tanaman.

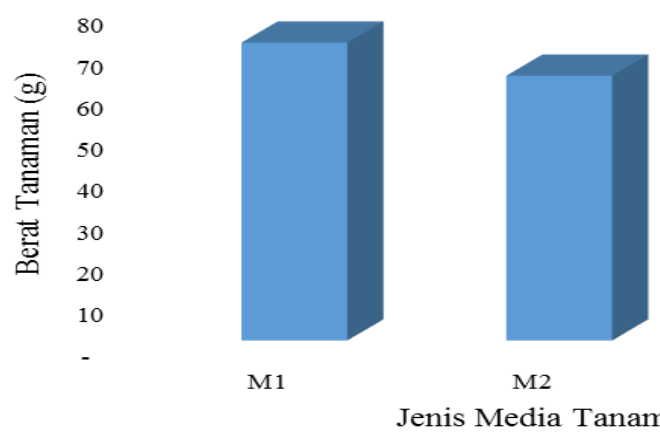

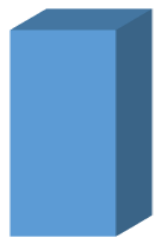

M3

Gambar 7. Histogram Pengaruh Jenis Media Tanam Terhadap Berat Tanaman (g) Selada.

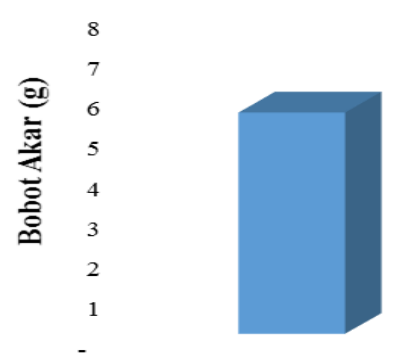

N1

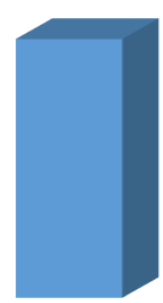

N2

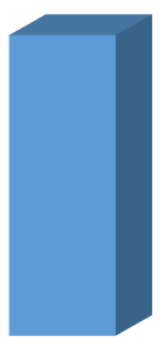

N3

Nutrisi Ab Mix

Gambar 8. Histogram Pengaruh Konsentrasi Nutrisi AB Mix Bobot Akar (g) Selada 
Tabel 1 dan 2 memperlihatkan bahwa pengaruh jenis media tanam rockwool $\left(\mathrm{M}_{1}\right)$ memberikan hasil terbaik untuk semua parameter. Hal ini disebabkan karena media rockwool mampu untuk menyimpan larutan nutrisi lebih banyak dibandingkan dengan media lainnya sehingga ketersediaan hara lebih banyak dalam media rockwool. Hal ini menyebabkan diperoleh hasil yang optimal terhadap pertumbuhan tanaman selada pada hidroponik baik pada tinggi tanamn, luas daun, bobot akar maupun bobot tanaman. Ketersediaan hara yang cukup mendukung dalam proses pertumbuhan dan perkembangan tanaman seperti proses pembelahan dan pembesaran sel. Hal ini sejalan dengan penelitian Syawaludin dan Harahap (2016) yang menyatakan media tanam rockwool merupakan media tanam dalam penelitian hidroponik system sumbu yang paling berpengaruh terhadap pertumbuhan dan hasil produksi tanaman. Dampak dari penggunaan media yang terlalu padat seperti penggunaan arang sekam dan cocopeat dapat menghambat pertumbuhan tanaman karena nutrisi yang akan diserap tanaman sulit untuk ditembus oleh akar. . Menurut Rahayu et al., (2008) media arang sekam dan cocopeat kurang mampu untuk menyimpan pupuk yang diaplikasikan dibandingkan dengan media tanam campuran (pasir + arang sekam) (tanah + cocopeat), karena terjadi penguapan sehingga penyerapan pupuk kurang optimal, dan penggunaan media tanam yang memiliki pori-pori baik merupakan media yang mampu menyimpan nutrisi yang baik pada budidaya dengan sistem hidroponik.

Semakin tinggi konsentrasi nutrisi ab Mix yang diberikan maka ketersediaan hara juga semakin baik sehingga pertumbuhan tinggi tanaman,luas daun, bobot akar dan bobot tanaman terlihat semakin bertambah. Hal ini sesuai dengan pernyataan Lawalata (2011), yang mengungkapkan bahwa pemberian unsur hara dapat meningkatkan pertumbuhan tanaman dalam jumlah yang sesuai kebutuhan tanaman. Jika terlalu berlebihan akan menyebabkan pertumbuhan menjadi terhambat. Semua hara yang terkandung pada nutrisi hidroponik adalah unsur esensial yang diperlukan tanaman dalam pertumbuhan dan perkembangannya. . Apabila unsur hara makro dan mikro tidak lengkap ketersediaannya, dapat menghambat pertumbuhan dan perkembangan tanaman (Perwitasari, 2012). Menurut Oviyianti (2016) kekurangan dan kelebihan Nitrogen menyebabkan pertumbuhan batang dan daun terhambat karena pembelahan dan pembesaran sel terhambat, sehingga bisa menyebabkan tanaman kerdil dan kekurangan klorofil. Dalam hal penelitian ini nutrisi ab mix belum nampak kelebihan karena konsentrasi 1200 ppm masih menunjukkan pertambahan dan perkembangan pertumbuhan dan produksi tanamna selada.

\section{KESIMPULAN}

Jenis media tanam berpengaruh nyata terhadap tinggi tanaman, luas daun, bobot akar, dan bobot tanaman. Jenis media tanam terbaik terdapat pada media rockwool.

Tingkat konsentrasi nutrisi $\mathrm{Ab}$ Mix berpengaruh nyata terhadap tinggi tanaman, luas daun, bobot akar, dan bobot tanaman. Tingkat konsentrasi nutrisi Ab Mix terbaik ialah 1200 ppm. 
Interaksi Jenis media tanam dan konsentrasi nutrisi $\mathrm{Ab}$ Mix berpengaruh tidak nyata namun hasil terbaik terdapat pada perlakuan $\mathrm{M}_{1} \mathrm{~N}_{3}$.

\section{DAFTAR PUSTAKA}

Andhika, R.L. 2017. Karakteristik Agronomis Tanaman Kailan (Brassica juncea L. Var. Acephala Dc.) Kultivar Full White 921 Akibat Jenis Media Tanam Organik dan Nilai Ec pada Hidroponik Sistem Wick. Jurnal Agroteknologi Indonesia 2 (1) : 25-33

Arifin, R. 2016. Bisnis Hidroponik Ala Roni Kebun Sayur. PT Agromedia. Jakarta.

\section{Badan Pusat Statistik. 2013. Produksi Sayuran di Indonesia 2007-2009. www.bps.go.id. (30 April 2014). Yogyakarta.}

Bambang H. I. dan Mulyono. 2016. Hidroponik Sistem Injeksi.

Hasriani, Dkk. 2013. Kajian Serbuk Sabut kelapa (Cocopeat) Sebagai Media Tanam. ITB. Bogor.

Lawalata, J. (2011). Pemberian Kombinasi ZPT terhadap Regenerasi Gloxinia Secara Invitro. Journal Exp Life Sci. Vol 1 No. 2. Fakultas Pertanian Universitas Pattimura. Ambon.

Lingga , P. 2005. Hidroponik Bercocok Tanam Tanpa Tanah. Penebar Swadaya, Jakarta.
Lingga, L. 2010. Cerdas Memilih Sayuran. Penebar Agro Media Pustaka. Jakarta.

Mas'ud, H. 2009. Sistem Hidroponik dengan Nutrisi dan Media Tanam Berbeda terhadap Pertumbuhan dan Hasil Selada. Media litbang, Sulteng.

Moehasrianto P. Respon pertumbuhan tiga macam sayuran pada berbagai konsentrasi nutrisi larutan hidroponik. Fakultas pertanian universitas jember. 2011.

Nugraha, R.U. 2015. Sumber Sebagai Hara Pengganti $A B$ Mix Pada Budidaya Sayuran Daun Secara Hidroponik. Jurnal Hortikultura Indonesia. Bogor.

Oviyanti, $\mathrm{F}$ Pengaruh pemberian pupuk organic cair daun (Gliricidia sepium (jacq) kunth ex walp) terhadap pertambahan tanaman sawi (Brassica juncea L.) UIN Raden Fatah. Palembang. 2016

Perwitasari, B. (2012). Pengaruh Media Tanam dan Nutrisi Terhadap Tanaman Pakcoy ( Brassica juncea) Secara Hidroponik. Jurnal Agrovigar Vol.5 No.1 Universitas Trunjoyo Madura..

Rahayu, M., Sumanhudi., dan A.S. Widodo. 2008. Pengaruh Macam Medai dan Konsentrasi Pupuk Fermentasi Ampas Tahu Terhadap Pertumbuhan dan Hasil Tanaman Sayuran Secara Hidroponik. 
Agroprimatech

Vol. 4 No. 2, April 2021

Saparinto, C. 2013. Gown Your Own Vegetables-Panduan

Praktis Menanam Sayuran Konsumsi Populer di Pekaranagan. Yogyakarta. 180 hal.

Setyaningrum, H. D dan C. Saparinto. 2011. Panen Sayur Secara Rutin di Lahan Sempit. Penebar Swadaya, Jakarta.

Setyoadji D. 2005. Tanaman Hidroponik. Araska 2015, Yogyakarta.

Syawaluddin, W, \& Harahap, I.S. (2016).

Pengaruh

Perbandingan Jenis Larutan

Hidroponik Dan Mediatanam Terhadap Pertumbuhan Serta Hasil Produksi Tanaman Sawi (Brassica Juncea. L) Drif Irrigation System. Jurnal Agrohita, 1(1), 38-53

Suhardiyanto, H. 2002. Pengenalan Hidroponik Substrat. Bogor:
e-ISSN :2599-3232

Creata-Lembaga Penelitian IPB.

Sunarjono, H. 2003. Fisiologi Tanaman Budidaya. UI Press. Jakarta. 428 Hal.

Sunarjono, H. 2014. Bertanam 36 Jenis Sayuran. Penebar Swadaya, Jakarta. $148 \mathrm{Hal}$.

Supriati, Y dan E. Herlina. 2014. 15 Sayuran Organik Dalam Pot. Penebar Swadaya. Jakarta. 148 hal.

Susila, A. D. 2006. Fertigasi pada Budidaya Tanaman Sayuran di dalam Greenhouse. Bagian Produksi Tanaman, Departemen Agronomi dan Hortikultura. Fakultas Pertanian. IPB. Bogor.

Wibowo, S. 2013. Aplikasi Hidroponik NFT pada Budidaya Pakcoy (Brassica rapa chinensis). Jurnal Penelitian Pertanian Terapan. Bogor. 